九州大学学術情報リポジトリ

Kyushu University Institutional Repository

Theoretical Analysis of Chemical Reaction in Frozen State (Part 2) : Introduction of a More Accurate Freezing Point Depression

Murata, Satoshi

Laboratory of Agricultural Process Engineering, Faculty of Agriculture, Kyushu University

Yamasaki, Nobuyuki

Laboratory of Biochemisty, Faculty of Agriculture, Kyushu University

Tanaka, Fumihiko

Laboratory of Agricultural Process Engineering, Faculty of Agriculture, Kyushu University

https://doi.org/10.5109/24032

出版情報: 九州大学大学院農学研究院紀要. 38 (1/2), pp.1-7, 1993-12. Kyushu University バージョン：

権利関係 : 


\title{
Theoretical Analysis of Chemical Reaction in Frozen State (Part 2) -I ntroduction of a More Accurate Freezing Point Depression -
}

\author{
Satoshi Murata, Nobuyuki Yamasaki* \\ and Fumihiko Tanaka \\ Laboratory of Agricultural Process Engineering, Faculty of Agriculture, \\ Kyushu University 45-05, Fukuoka 812, Japan \\ (Received A pril 2, 1993)
}

\begin{abstract}
Acceleration of chemical reactions in the frozen state has become of interest in recent years because of its unique characteristics. To give a theoretical interpretation for the acceleration mechanism of such reactions, a new equation is derived. The equation is essentially the product of Arrhenius formula of temperature effect and the term of liquid concentration varied with freezing ratio. In the previous paper (Murata et al., 1992), for calculating the freezing ratio the Heiss formula was used. In this case, a more accurate freezing point depression is introduced and the error of the optimum temperature of reaction between calculated result and experimental result is reduced from $1.8^{\circ} \mathrm{C}$ to $0.2^{\circ} \mathrm{C}$.

For calculation, the kinetic data obtained for the acid-catalyzed deformilation of $\mathrm{N}$ acetyl-N'-formly-L-kynureninneamide (Yamasaki et al., 1976b) are used.

The results clearly indicate that the calculated first -order rate constants at various temperatures are in good agreement with the experimental data.

The acceleration of the deformylation of $\mathrm{N}$-formylkynurenine in the frozen acidic solutions can be interpreted as being due to the concentration of the reactants in the liquid region in ice crystals.
\end{abstract}

\section{INTRODUCTION}

It has recently been shown that acceleration of chamical reactions in frozen state and has become of interest of its unique characteristics (Aso, 1990, Grant, 1961, Kiovsky, 1966, Prusoff, 1963 and Yamasaki, 1976b). These reactions are closely related with food industries, then if a theoretical interpretation for the acceleration mechanism of such reactions are given, it may be obtained some basic information for the deterioration of foods during partial freezing storage or freeze drying process.

From this point of view, the acceleration of the deformylation of $\mathrm{N}$-acetyl-N'-formyl$\mathrm{L}-$ kynureninneamide (NFK) in the frozen acidic solutions is studied. NFK is a medium product of tryptophan metabolism, which is obtained from tryptophan by using tryptophan-2,3 -Oxygen or which is obtained as oxidation product of tryptophan by ozone. Futhermore, formic acid and kynurenine (Kyn) are obtained from the acidcatalyzed deformilation of NFK by acid or formamytase. Yamasaki et al. (1976) have found that the reaction of acid-catalyzed hydrolysis of the formamide linkage of NFK was accelerated in frozen dilute hydrochloric acid solution. By applying the above chemical modification method to the oxidized lysozyme, they have obtained a lysozyme derivative, 1-NFK-lysozyme, in which tryptophan 62 was substituted by $\mathrm{N}^{\prime}$-formylknurenine and this finding shows that above chemical modification may be useful for

*Laboratory of Biochemisty, Faculty of Agriculture, Khushu University 46 -02, Fukuoka 812, Japan 
analysis of relationship between lysozyme structure and that function (Yamasaki et al., 1976ab, 1980, 1988a, 1990, 1991).

The reaction of the deformylation of NFK in the frozen state had very unique characteristics and the kinetic analysis was carried out in detail by using the model chemical compound $\left(\mathrm{N}-\right.$ acetyl $-N^{\prime}-$ formyl $-_{L}-$ kynureninneamide). But, the theoretical interpretation for this acceleration of chemical reaction had never been given. In this study, to give a theoretical interpretation for the mechanism of this reaction, a new equation was derived. The equation was based on Arrhenius formula and the theory of "the concentration effect" which was founded on solid- liquid phase equilibrium. It was clear that the reaction of deformylation of NFK in dilute hydrochloric acid solution could be explained theoretically by using this equation.

\section{THEORY}

\section{Rate exation}

The reaction of the deformylation of N'-formylkynurenine in the frozen and liquid of acidic solutions follows first -order kinetics (Yamasaki, 1976b), and the rate of reaction was correlated by the eq. (1).

$$
-\frac{d[A]}{d \theta}=k[A]
$$

where as :

$$
\begin{aligned}
& \text { [A] : the concentration of reactant } \\
& \mathrm{e} \text { : reaction time } \\
& k \quad \text { : first-order rate constant }
\end{aligned}
$$

The first-order rate constant which was given as following Arrhenius formula (2)

$$
k=k o \exp \left(-\frac{E}{R \cdot T}\right)
$$

where as :

$$
\begin{array}{ll}
E & \text { : activation energy in } \mathrm{kJ} \cdot \mathrm{Mol}^{-1} \\
R & \text { : ideal gas constant }\left(=8.314 \mathrm{~kJ} \cdot \mathrm{K}^{-1} \cdot \mathrm{Mol}^{-1}\right) \\
T & \text { : the absorbed temperature in } \mathrm{K}
\end{array}
$$

\section{The introduction of new simulation equation of freezing point depression}

The' rate constants of reaction in the liquid solution shoud be calculated in accuracy by Arrhenius formula eq. (2), of course, as stand above. But the reactants were concentrated in liquid region in ice crystal when the solutions were frozen, so it was needed for giving a theoretical interpretation to take eq. (1) into account of "the effect of concentration", i.e. the left side term $[A]\left([A]_{\mathrm{L}}\right)$ in eq. (1) was initial concentration of solution but the other side $\left.[A]\left([A]_{R}\right)\right]$ was the concentrated fraction caused on freezing the solution. Hence $[A] \mathrm{R}$ shoud be calculated from freezing fraction.

The freezing fraction was shown by the thermodynamic expression of phase equilibrium for non-ideal solution (unpublished paper by Murata). In this study the phase equilibrium on the assumption that the solid reactants insolve together but these 
liquids dissolve together, were used as the following eq. (3).

$$
\mathrm{A} \mathrm{T}=-\frac{R \cdot T \cdot T_{0}}{\mathbf{A} \mathbf{H}} \cdot \ln \left(\frac{1-X_{S}}{1-X_{S}+\mathrm{ax},+\beta X_{S}{ }^{2}}\right)
$$

where as :

AH : latent heat of melting in $\mathrm{kJ} / \mathrm{Mol}$

$X_{S} \quad$ : mass fraction of solution in decimal

$0 \quad$ : denotes the freezing point of pure water

Parameters ( $\alpha$ and $\beta$ ) were calculated from typical data for hydrochloric acid solution (Weast, 1985) by using the Deming method, i.e. $\alpha$ was 0.809 and $\beta$ was 7.164.

Then the freezing fraction $(\psi)$ was represented by the following eq. (4).

$$
\psi=1-\frac{X_{f}}{X_{S}}
$$

Rearranging eq. (4), the unfrozen fraction $(1-\psi)$ became

$$
\begin{aligned}
& 1-\psi=\frac{X_{f}}{X_{S}} \\
& X_{S}=\frac{-(1-\delta+\alpha \cdot \delta)+\left\{(1-\delta+\alpha \cdot \delta)^{2}-4 \beta \cdot \delta(\delta-1)\right\}^{0.5}}{2 \beta \cdot \delta}
\end{aligned}
$$

where as :

$$
\delta=\exp \left\{-(\Delta H \cdot \Delta T) /\left(R \bullet T \cdot T_{o}\right)\right.
$$

Then the concentration of liquid region in ice crystals was $A_{o}\left(X_{S} / X_{f}\right)$ where as :

Ao : initial concentration of solution.

Eq. (1) was rearranged to the following :

$$
-\frac{d[A]}{d \theta}-A_{O} \cdot\left(X_{S} / X_{f}\right) \cdot \exp \quad\left\{\frac{-E}{R \cdot(273.15+t)}\right\}
$$

After all, the simplest expression of chemical reaction which had a maximum rate point in frozen state was shown by above eq. (8). This equation was essentially based on the Arrhenius formula and new simulation equation of freezing point depression. Eq. (8) were derived by taking into account of the concentration effect caused on freezing the solution.

The reaction in liquid state, however, follows eq. (9).

$$
-\frac{d[A]}{d \theta}=A_{o} \cdot k_{o} \cdot t \cdot \exp \left\{\begin{array}{c}
-E \\
R \cdot(273.15+t)
\end{array}\right\}
$$




\section{S. Murata et al.}

\section{RESULTS AND DISCUSSION}

\section{Determination of parameters}

For analyzing the acceleration of chamical reactions in frozen state, the data of the spectral absorption change at $360 \mathrm{~nm}$ observed during the acid-catalyzed deformylation reaction of the model kynurenine derivative in the frozen and liquid of $0.025 \mathrm{M}$ dilute hydrochloric acid solution was used (Yamasaki, 1976b). This data in Table 1 and figure 1 indicates the plot of $\log k$ against $1 / T$ in liquid and in frozen solutions at constant initial concentrations. The first - order rate constant in liquid solution decreases when the temperature degree decreasing. The broken line in Fig. 1 was calculated resluting from eq. (10), it should be confirmed that the reaction of the deformylation of NFK in liquid acidic solution Arrhenius was depending on the type of temperature. At this time, activation energy $(E)$ and parameter $\left(k_{o}\right)$ were introduced by the least squares method, i.e. $E=61700 \mathrm{~kJ} \cdot \mathrm{Mol}^{-1}, k_{0}=19.1 \mathrm{~min}^{-1}$ (standard deviation was $\left.0.24 \times 10^{-3} \mathrm{~min}^{-1}\right)$. Further, this-depending to realized in super-cooled liquid solution at $-8^{\circ} \mathrm{C}$, its deformation reaction was very slow and $k$ was $0.15 \times 10^{-3} \mathrm{~min}^{-1}$. It was supposed that the reaction in liquid region in frozen solution as follow the Arrhenius formula.

Table 1. Observed first-order rate constant for acid-catalyzed hydrolysis of the formamide linkage of $\mathrm{N}$-acetyl-N'-formyl-r_-Kynurenineamide

\begin{tabular}{cccc}
\hline \multicolumn{3}{c}{ Frozen state } & \multicolumn{3}{c}{ Liquid state } \\
\hline $\begin{array}{c}\text { Temp } \\
\left({ }^{\circ} \mathrm{C}\right)\end{array}$ & $\begin{array}{c}\mathrm{k} \times 10^{3} \\
\left(\mathrm{~min}^{-1}\right)\end{array}$ & $\begin{array}{c}\text { Temp } \\
\left({ }^{\circ} \mathrm{C}\right)\end{array}$ & $\begin{array}{c}\mathrm{k} \times 10^{3} \\
\left(\mathrm{~min}^{-1}\right)\end{array}$ \\
\hline-26 & 4.15 & -8 & $0.15^{* *}$ \\
-17 & 5.76 & +7 & 0.60 \\
-16 & 6.45 & +15 & 1.42 \\
-13 & 7.37 & +20 & 2.26 \\
-12 & 7.60 & +27 & 3.70 \\
-8 & 8.75 & +30 & 4.95 \\
-7.5 & 9.35 & +36 & 8.19 \\
-5 & 7.60 & +40 & 10.20 \\
-3 & 6.67 & & \\
-2 & 5.29 & & \\
-1 & 4.60 & & \\
& $* *$ Super-cooled liquid solution. & \\
The rate constant was calculated from the spectral change (at $360 \mathrm{~nm})$ measured \\
during the deformylation of N-acetyl-N'-formyl-L-kynurenineamide in frozen and \\
liquid of 0.025 M dilute hydrochlonic acid solutions.
\end{tabular}

On the other hand, the reaction rate was accelerated in frozen solution and the maximum rate of reaction was found at $-7.5^{\circ} \mathrm{C}$ and approximated that of the reaction in liquid solution at $40^{\circ} \mathrm{C}$.

Hence, to give a theoretical interpretation for the acceleration mechanism of such reaction, a new theoretical equation ((8)) was used. 


\section{Calculated results}

The curved broken line in Fig. 1 was calculated resulting from fitting to eq. (9) by the least squares method. And the curved solid line 1 was calculated from eq. (10) (refer appendix) and it had a maximum rate point at $-9.3^{\circ} \mathrm{C}$ (the standard deviation was $1.145 \times 10^{-3} \mathrm{~min}^{-1}$. The curved solid line 2 was calculated from eq. (8) and it's maximum rate point was $-7.3^{\circ} \mathrm{C}$. The calculated optimum temperature using eq. (8) for hydrolysis of NFK in frozen solution was in better agreement with experimental data than calculated from eq. (10). The results clearly indicated that the calculated first-order rate constantat (from eq. (8) ) under various temperatures were quite agreed well with the experimental data, and it's standard deviation was $1.144 \times 10^{-3} \mathrm{~min}^{-1}$. The standard deviations of calculated first-order rate constantat using eq. (8) and eq. (10) were almost same (see Table 2). And the standard deviation of the differance between data and simulated values from eq. (8) (frozen state) was little bigger than that from eq. (9) (unfrozen state).

Table 2. Parameters and its standard deviations

\begin{tabular}{c|c|c}
\hline & \multicolumn{2}{|c}{ Parameters } \\
\hline Eq. (8) & $\alpha=0.809, \beta=7.164$ & \multirow{2}{*}{$E=61700\left(\mathrm{~kJ} \cdot \mathrm{Mol}^{-1}\right)$} \\
\hline Eq. (10) & $k_{f}=-0.137\left({ }^{\circ} \mathrm{C}\right)$ & Standard deviation \\
\hline Eq. (8) & Maximum rate point & $1.144 \times 10^{-3}\left(\mathrm{~min}^{-1}\right)$ \\
\hline Eq. (10) & $-7.3\left({ }^{\circ} \mathrm{C}\right)$ & $1.144 \times 10^{-3}\left(\mathrm{~min}^{-1}\right)$ \\
\hline
\end{tabular}

*The experimental maximum rate point is $-7.5^{\circ} \mathrm{C}$

The above results showed that the solution associated with it's frozen state, continues to progress chemical reactions having the same constant activation energy as when it is under a unfrozen state. And the acceleration of chemical reaction in the frozen acidic solutions could be interpreted as being due to the concentration of the reactants in the liquid region in ice crystals.

It had been indicated that "the effect of concentration" was very important factor for deterioration of protein in frozen foods (Yamasaki, 1988b), so it was expected that this theory became a useful method for frozen food science.

\section{ACKNOWLEDGEMENTS}

The authors wish to acknowledge the help of Mr. K.S.P. Amaratunga and Mr. 
Hussein Sorour, who provided many helpful suggestions.

\section{REFERENCES}

Aso, Y., Yamasaki, Hatakeyama and Gotho 1990 Agric. Biol.Chem., 54: pp. 2187

Barrow, G. M., Transl. by Fujishiro, R. 1990 Physical Chemistry 5th ed, Tokyo Kagaku Dozin, Tokyo, pp. 315, 441

Grant, N. H., Clark and Alburn 1961 J. Am. Chem. Soc., 83: pp. 4476

Heiss, R. 1933 Zeitschrift fur dieka lte-Industrie, 40: pp. 53

Heiss, R. and Schachinger 1951 Food Technology. 5 (6): pp. 211

Kiovsky, T. E. and Pincock 1966 J. Am. Chem. Soc., 88: pp. 4704

Maruoka, T., Yamashita, Abe and Yamasaki 1991 Agric. Biol.Chem., 55: pp. 2151

Murata, S., Yamasaki and Tanaka 1992 Journal of the Japanese Society for Food Science and Technology, $39(11)$ : pp. 972

Prusoff, W. H. 1963 Biochim. Biophys, Acta., 68: pp. 302

Teshima, K., Kuramitsu, Hamaguchi, Sakiyama, Mizuno and Yamasaki 1980 J. Biochem., 87: pp. 1015

Yamasaki, N., Tsujita, Sakiyama and Narita 1976a J. Biochem., 80: pp. 409

Yamasaki, N., Tsujita, Sakiyama and Masuda 1976b J. Biochem., 80: pp. 1287

Yamasaki, N., Tsujita, Etho, Masuda and Sakiyama 1979 J. Biochem., 86: pp. 1291

Yamasaki, N., Etho and Sakiyama 1988a Agric. Biol. Chem., 52: pp. 2333

Yamasaki, N., Etho and Sakiyama 1988b Agric. Biol.Chem., 52: pp. 2547

Yamasaki, N., Etho and Sakiyama 1990 Agric. Biol. Chem., 54: pp. 1883

\section{APPENDIX}

In the previous paper (Murata et al. 1992), the freezing ratio was calculated from the Heiss formula, and next equation was derived.

$$
-\frac{\mathbf{a}^{\prime}[A]}{d \theta}=A_{O} \cdot k_{O}^{\prime} \cdot t \cdot \exp \quad\left\{\frac{-E}{R \cdot(273.15+t)}\right\} \quad \cdots \cdots \cdot \cdot(10)
$$

where as :

$$
t \quad \text { : temperature in }{ }^{\circ} \mathrm{C}
$$

and $k_{\mathrm{o}}^{\prime}=k_{0} / t_{f}$

Hence freezing point, $t_{f}=-0.137^{\circ} \mathrm{C}$ was determined from experimental data in frozen and super -cooled liquid solutions at $-8^{\circ} \mathrm{C}$. This freezing point is lower than theorecal that of $0.025 \mathrm{M}$ dilute hydrochloric acid solution $\left(-0.092^{\circ} \mathrm{C}\right)$, but by assuming $t_{f}=-0.137$ " $\mathrm{C}$, the calculated rate constants of the present reaction at various temperature were in good agreement with experimental data. 


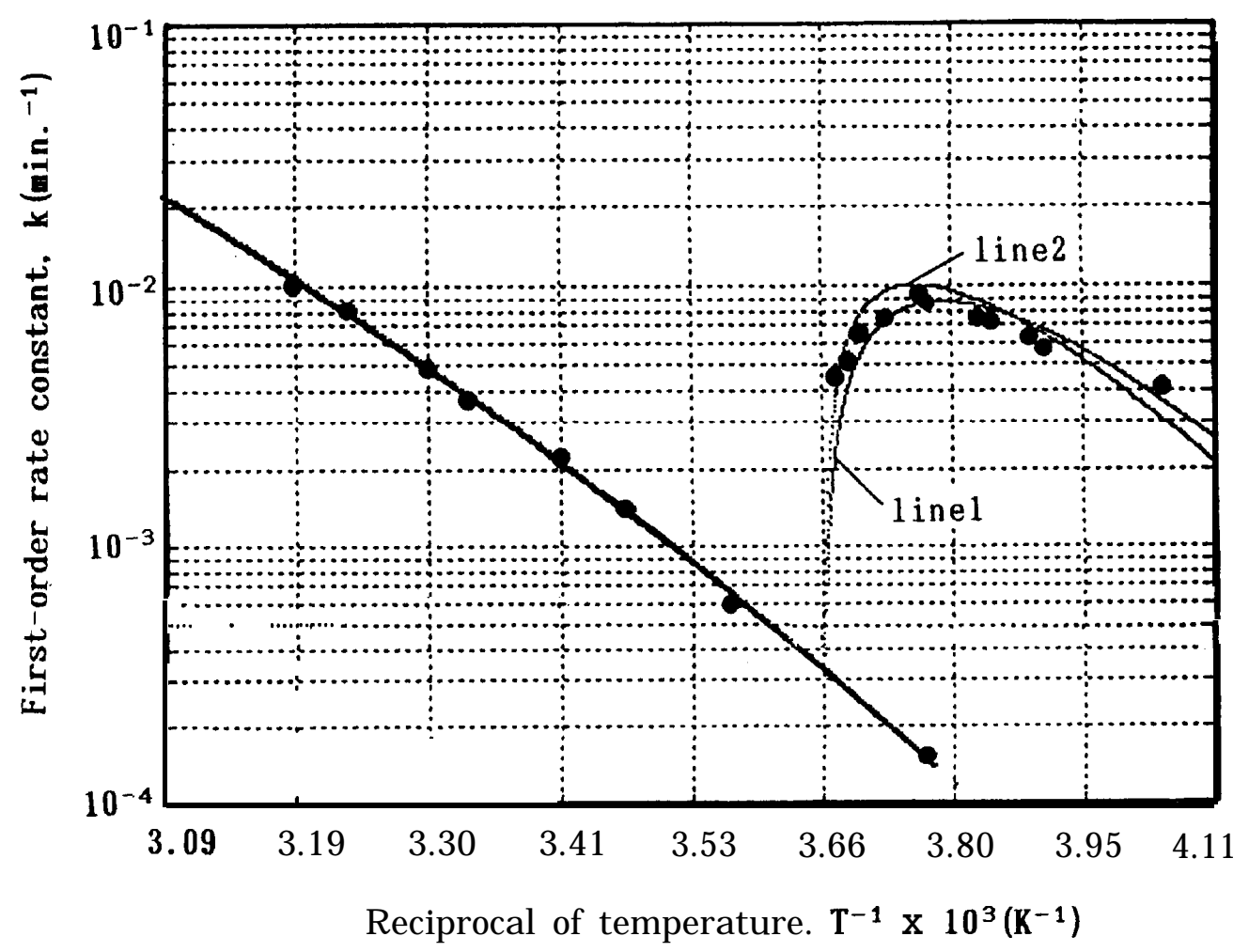

Fig. 1. Temperature dependence of observed rate constant (curved lines are calculated from eq. (8) and eq. (10)) 